\title{
DINHEIRO, DEMOCRACIA E A (SUB) REPRESENTAÇÃO DAS MULHERES NAS ELEIÇÕES DE 2008, 2012 E 2016 NO BRASIL
}

\author{
Adriana Aurea Mota Bueno ${ }^{1}$ \\ Ivan Jairo Junckes ${ }^{2}$
}

\begin{abstract}
Resumo
O efeito do dinheiro nos resultados das campanhas eleitorais é um dos principais questionamentos dos estudos sobre o financiamento eleitoral na ciência política. O objetivo deste artigo é discutir as relações de influência dos recursos financeiros sobre o fenômeno da sub-representação das mulheres na política no Brasil. Dada a forte correlação entre dinheiro, voto e sucesso eleitoral, a principal hipótese deste trabalho é que a assimetria dos recursos destinados aos homens e mulheres tem forte influência para a produção da sub-representação das mulheres na política. A fonte de dados é o Tribunal Superior Eleitoral, a população estudada foi os candidatos(as) para vereadores(as) em municípios com mais de 50.000 eleitores e o recorte temporal as eleições de 2008, 2012 e 2016. Para o tratamento de dados foram utilizados recursos de planilha de dados e estatística descritiva e inferencial, especialmente as análises de correlação e regressão linear ou logística para verificar a relação entre recursos arrecadados e votação, sucesso eleitoral e demais atributos dos candidatos. Entre os resultados desta pesquisa, destaca-se que a tentativa de ingresso na vida política revela uma maior probabilidade de homens terem suas candidaturas aptas do que as mulheres. Para a hipótese principal, a qual foi respondida pelo coeficiente de correlação de Pearson, verifica-se uma correlação forte e positiva entre dinheiro arrecadado em campanhas e o sucesso eleitoral. Corroborando a literatura, o financiamento político dos homens se apresentou superior ao das mulheres. Mesmo com valores de arrecadação e perfil semelhantes, ainda assim, os homens se elegem mais.
\end{abstract}

Palavras-Chave: Eleições. Financiamento Eleitoral. Mulheres. Gênero.Câmara de Vereadores.

\begin{abstract}
The effect of money on the results of electoral campaigns is one of the main questions of studies on election finance in political science. The aim of this article is to discuss the influence of financial resources on the phenomenon of under-representation of women in politics in Brazil. Given the strong correlation between money, voting and electoral success, the main hypothesis of this work is that the asymmetry of medical resources between men and women has a strong influence on the production of underrepresentation of women in politics. The data source is the Superior Electoral Court, the population studied were candidates for councilors in municipalities with more than 50,000 voters and the time frame as updates of 2008, 2012 and 2016. As for the data processing, data sheet resources and descriptive and inferential statistics were used, especially the correlation analysis and linear or logistic regression to verify the relationship between collected resources and voting, electoral success and other candidate attributes. Among the results of this research, it is highlighted that the attempt to enter political life reveals a greater probability of men having their candidacies suitable than women. For the main hypothesis, which was answered by the Pearson correlation coefficient, there is a strong and positive correlation between money collected in campaigns and electoral success. Corroborating the literature, the political funding of men has been shown to be superior to that of women. Even with similar fundraising values and profile, men are still more elected.
\end{abstract}

Keywords: Elections. Electoral Financing. Women. Gender.Chamber of councilors.

1Mestre (2020) em Desenvolvimento Territorial Sustentável pela Universidade Federal do Paraná (UFPR), Setor Litoral. Faz parte do grupo que atua no Laboratório de Análise de Redes (LAR/UFPR). -Email: adriana.a.bueno@gmail.com

2 Doutor (2004) em Sociologia Política pela Universidade Federal de Santa Catarina - UFSC. Professor na Universidade Federal do Paraná (UFPR), Setor Litoral, no Curso de Administração Pública e no Programa de PósGraduação em Desenvolvimento Territorial Sustentável - PPGDTS. Líder do grupo de pesquisas Laboratório de Análise de Redes (LAR/UFPR) onde desenvolve pesquisas em análise de redes sociais (ARS) e financiamento eleitoral. E-mail: ivanjairojunckes@gmail.com 
BUENO, A. A. M.; JUNCKES, I. J. Dinheiro, democracia e a (sub) representação das mulheres nas eleições de 2008, 2012 e 2016 no Brasil. DOI: http:/ /dx.doi.org/10.5380/recp.v11i2.81598

\section{Resume}

El efecto del dinero en los resultados de las campañas electorales es una de las principales cuestiones de los estudios sobre financiación electoral en ciencia política. El objetivo de este artículo es discutir la influencia de los recursos financieros en el fenómeno de la subrepresentación de las mujeres en la política en Brasil. Dada la fuerte correlación entre dinero, voto y éxito electoral, la principal hipótesis de este trabajo es que la asimetría de recursos asignados a hombres y mujeres tiene una fuerte influencia en la producción de subrepresentación de las mujeres en la política. La fuente de datos es el Tribunal Superior Electoral, la población estudiada fueron los candidatos a concejales en los municipios con más de 50.000 electores y el marco temporal de las elecciones de 2008, 2012 y 2016. Se utilizaron recursos de hoja de datos y estadísticas descriptivas e inferenciales, especialmente correlación análisis y regresión lineal o logística para verificar la relación entre los recursos recolectados y la votación, el éxito electoral y otros atributos de los candidatos. Entre los resultados de esta investigación, se destaca que el intento de ingresar a la vida política revela una mayor probabilidad de que los hombres tengan sus candidaturas adecuadas que las mujeres. Para la hipótesis principal, que fue respondida por el coeficiente de correlación de Pearson, existe una correlación fuerte y positiva entre el dinero recaudado en las campañas y el éxito electoral. Corroborando la literatura, el financiamiento político de los hombres fue superior al de las mujeres. Incluso con valores y perfil de recaudación de fondos similares, los hombres siguen siendo más elegidos.

Palabras-clave: Elecciones. Financiamiento electoral. Mujeres. Género. Cámara de Concejales.

\section{INTRODUÇÃO}

O presente trabalho é resultado de uma pesquisa ${ }^{3}$ sobre financiamento eleitoral e participação política das mulheres visando contribuir com as discussões acerca da (sub) representação desta metade da população brasileira.

A representação feminina no Brasil destaca-se negativamente no quadro mundial. Em estudo sobre a participação das mulheres em diferentes países, desenvolvido anualmente pela União Interparlamentar (UIP), o Brasil ocupava a $167^{a}$ posição entre 186 países no ranking mundial de participação das mulheres no executivo em 2017. Em relação as cadeiras no parlamento ocuparam a $154^{a}$ posição no mundo com 10,7\% de mulheres na câmara dos deputados. Já em 2019, houve uma melhora, passou-se para $134^{a}$ posição no parlamento, porém, está longe de ser considerado um modelo de (ou com) representatividade feminina. Mesmo o eleitorado feminino sendo maioria (52\%), nas eleições de 2016 apenas 13,5\% das mulheres foram eleitas ${ }^{4}$.

Pesquisas (AVELAR, 2001; MIGUEL; QUEIROZ, 2006; PERISSINOTO et al., 2007; BOLOGNESI; PERISSINOTTO; CODATO, 2016; DUFLOTH et al., 2018) vêm demonstrando que a política é ocupada por quem apresenta certas características como cor, sexo e posição social,

3 Resultado da dissertação apresentada no PPGDTS/UFPR no período de 2018-2020. Para o presente artigo, apresenta-se resultados parciais da pesquisa.

4 Dados disponibilizados no site do Tribunal Superior Eleitoral sobre as eleições de 2016, referentes ao cargo de vereador. 
BUENO, A. A. M.; JUNCKES, I. J. Dinheiro, democracia e a (sub) representação das mulheres nas eleições de 2008, 2012 e 2016 no Brasil. DOI: http://dx.doi.org/10.5380/recp.v11i2.81598

ou seja, o grupo de governantes é formado por brancos, de sexo masculino, ricos e muito mais instruídos do que o conjunto da população.

Apesar das legislações de estímulo ${ }^{5}$ e relativa proteção, não houve uma mudança significativa na participação relativa das mulheres entre os eleitos. Sacchet et al. (2012) destacam que a subrepresentação das mulheres na política não pode ser relacionado apenas a uma questão de oferta e pontua que ainda que o número de candidatas seja relativamente pequeno o número de eleitas é ainda menor. Entre as candidaturas consideradas aptas e a condição de eleitos nos municípios acima de 50.000 eleitores, na eleição de 2008 as mulheres foram 23,5\% de candidaturas aptas e 10,4\% de eleitas, em 2012 foram 30,4\% elegendo os mesmos 10,4\% e em 2016 31,2\% e 11\% entre o total de eleitos.

A viabilidade de candidaturas e o sucesso eleitoral apresentam relação direta com a quantidade de recursos financeiros investidos em campanha, ou seja, dinheiro, voto e sucesso eleitoral são "íntimos". Quanto mais o candidato mobiliza investimentos, mais chances têm de viabilizar sua candidatura e de se eleger, sendo que o inverso também ocorre: quanto menos recursos, as chances diminuem significativamente (CARLOMAGNO; CODATO, 2018; JUNCKES et al., 2019).

A Lei 13.165/2015 modificou as regras do financiamento eleitoral, tornando o financiamento empresarial ilegal com o objetivo de tornar a competição eleitoral mais justa e democrática. Segundo Mancuso (2015), em 2014 o financiamento concentrava-se em poucas empresas que financiavam quase que a totalidade dos candidatos, tal concentração econômica ocorre especialmente em candidaturas masculinas (SILVA et al., 2017). Todavia, não se pode apontar apenas como explicação das desigualdades do financiamento eleitoral as empresas doadoras, pois a forma com que os partidos gerenciam a divisão dos recursos aparece de forma desequilibrada e são apontados como aqueles que distribuem os recursos de forma mais desigual (SILVA, 2016).

Visando a contribuir com os desafios e discussões sobre a participação das mulheres na política no Brasil, a presente pesquisa investiga qual a influência dos recursos financeiros sobre a sub-representação das mulheres nos municípios com mais de 50.000 eleitores nas eleições de 2008, 2012 e 2016 no país. A hipótese principal foi de que o dinheiro tem grande influência no êxito eleitoral e que a forma com que os recursos são distribuídos entre os sexos, desfavorece as campanhas das mulheres.

Os dados utilizados têm origem no Tribunal Superior Eleitoral (TSE) e passaram por depuração, tabulação e organização no Grupo de Estudos Territoriais (GETE), da Universidade

5 A Lei n ${ }^{\circ} 9.504 / 97$ artigo $10^{\circ}$, parágrafo $3^{\circ}$ destaca que o mínimo de $30 \%$ e o máximo de $70 \%$ devem ser destinados a candidatos de cada sexo. 
BUENO, A. A. M.; JUNCKES, I. J. Dinheiro, democracia e a (sub) representação das mulheres nas eleições de 2008, 2012 e 2016 no Brasil. DOI: http://dx.doi.org/10.5380/recp.v11i2.81598

Estadual de Ponta Grossa (UEPG/PR), e no Laboratório de Análise de Redes (LAR), da Universidade Federal do Paraná (UFPR/Setor Litoral). O banco de dados utilizado foi composto de 79.420 candidaturas aptas em 2008, 113.488 em 2012 e 124.199 em 2016.

Para os procedimentos de processamento e análise dos dados utilizou-se de recursos de estatística descritiva e inferencial. Para verificar a correlação entre o dinheiro investido em campanhas e os votos recebidos pelas candidatas ao cargo de vereadora nas eleições municipais ocorridas nos anos de 2008, 2012 e 2016 foram realizados testes de correlação. Foram também realizados testes para investigar quais atributos (tais como escolaridade, idade, estado civil, carreira política, incumbência) estão associados e a sua influência na arrecadação de recursos financeiros pelas candidatas ao cargo de vereador (a) nas eleições municipais ocorridas nos anos de 2008, 2012 e 2016.

Foram utilizadas planilhas eletrônicas e o software Jamovi para a estatística descritiva de médias, medianas, desvio padrão, contagens e porcentagens, de acordo com a categorização das variáveis. Adicionalmente foram realizados testes de comparação de médias (Teste T), testes de associação Qui-Quadrado (quartis e tabelas de contingência) ou alternativo não paramétrico teste de Wilcoxon-Mann-Whitney, para identificar diferenças entre grupos. Além das análises mencionadas, foram aplicados testes de correlação e regressão linear para as variáveis quantitativas, e regressão logística para variáveis categóricas para identificar padrões de predição de valores a partir das variáveis explicativas.

O texto que segue está dividido em duas partes além desta introdução e das considerações finais. No primeiro tópico, aborda-se as consequências do fortalecimento da divisão do público e privado para o reconhecimento da mulher como sujeito político, além de abordar possíveis explicações para a sub-representação das mulheres no espaço eleitoral. Na última parte apresentase os resultados da pesquisa, seguido das considerações finais.

\section{A MULHER COMO SUJEITO POLÍTICO E O ESPAÇO PRIVADO}

A sub-representação feminina na política tem sido estudada e debatida tanto na esfera pública quanto acadêmica sob diversos aspectos. Os questionamentos sobre papéis definidos, divisão sexual do trabalho e atribuições de homens e mulheres se combinam com as mudanças políticas, sociais e econômicas no final do século XVIII, ao passo que os homens conquistavam direitos de cidadania, à mulher era conferida a sujeição.

Segundo Pateman (2013), um dos motivos pelos quais as mulheres continuam marginalizadas na política, estaria na ausência de transformação no âmbito privado, reforçando o lugar de 
BUENO, A. A. M.; JUNCKES, I. J. Dinheiro, democracia e a (sub) representação das mulheres nas eleições de 2008, 2012 e 2016 no Brasil. DOI: http://dx.doi.org/10.5380/recp.v11i2.81598

submissão das mulheres. Para a autora, a entrada na arena política, com o direito ao voto e a participação, não foi suficiente para colocar as mulheres em pé de igualdade com os homens. $\mathrm{O}$ reconhecimento da igualdade civil das mulheres veio combinada com a sujeição social.

Em 1792, Mary Wollstonecraft já denunciava o caráter excludente da Constituição Francesa de 1791 que incorporava a Declaração dos Direitos dos Homens e dos Cidadãos. A obra aponta os prejuízos da não inclusão das mulheres como cidadãs, condenadas a vida doméstica, sem acesso aos direitos básicos, em especial à educação, o que as tornava dependentes dos homens, pais, maridos ou irmãos (MORAES, 2015).

Pioneiro na discussão dos direitos civis das mulheres, Stuart Mill em 1869, na obra “A Sujeição das Mulheres”, já apontava que a subordinação de um sexo a outro era um dos principais obstáculos para o desenvolvimento humano. Destacando que a “justificativa” para tal subordinação se encontrava na inferioridade da força muscular das mulheres, e, portanto, estavam em condição de escravidão em relação a algum homem.

Para o autor, a aceitação deste sistema desigual nunca foi o resultado de deliberação. A autoridade dos homens sobre as mulheres não resulta de algum tipo de comparação consciente que leve em conta os diferentes modos de constituição de governo da sociedade e diferentes modos de organização social, como por exemplo, um possível governo de mulheres sobre homens. Muito menos leva em conta a forma com que as mulheres estão totalmente sujeitas aos homens, sem acesso à participação em assuntos públicos, obrigadas à obediência aos homens. O que prevaleceu para a desigualdade de direitos entre homens e mulheres foi a lei dos mais fortes.

Pateman (2013) sinaliza que Mill mostra na teoria o que o movimento feminista contemporâneo tem mostrado na prática, que as esferas pública e privada são intrínsecas e que a participação plena e igual das mulheres na vida pública, depende de uma mudança na esfera doméstica. Argumentos que desprezam a relevância política da esfera privada contribuem para deixar as coisas como estão, a tirania doméstica deve ser considerada contraditória aos preceitos de cidadania. A redistribuição das tarefas e responsabilidades domésticas de modo a igualar o trabalho de homens e mulheres se torna um imperativo da democracia, pois, a divisão doméstica do trabalho influencia diretamente o grau de envolvimento político (PHILLIPS, 2011).

A cultura instituída aponta que a mulher tem apatia pelo cenário político, todavia, Scott (2005) aborda essa "apatia" lembrando dos direitos historicamente negados as mulheres, bem como aos pobres e aos negros escravizados. As mulheres tinham suas vidas direcionadas ao cuidado e aos afazeres domésticos e sem direito à educação, sendo um impeditivo à participação política e à representação legal (direito ao voto e à elegibilidade). 
BUENO, A. A. M.; JUNCKES, I. J. Dinheiro, democracia e a (sub) representação das mulheres nas eleições de 2008, 2012 e 2016 no Brasil. DOI: http://dx.doi.org/10.5380/recp.v11i2.81598

No Brasil não foi diferente, chega-se no momento da conquista do voto feminino em 1932, com menos de um terço das mulheres alfabetizadas. Quase metade da população do período estava impedida de votar e se eleger, lembrando que só em novembro de 1985 os iletrados puderam exercer o direito ao voto (TELES, 1999).

Esses direitos historicamente negados, refletem na participação política das mulheres, a falta de tempo, relacionado a dupla jornada que enfrentam, tem sido elencado como um fator impeditivo para o envolvimento das mulheres com as questões públicas.

Esse cenário de exclusão das mulheres, reflete como os partidos encaram a presença feminina nos espaços de decisão, mesmo com a criação de políticas afirmativas (Lei n 9.504/97), a maioria dos partidos têm se utilizado das candidaturas apenas para cumprir o mínimo estabelecido por lei, sem um interesse efetivo nas candidaturas femininas, ocasionando, entre as mulheres um elevado percentual de candidaturas inaptas por renúncias e indeferimentos, apontando para a engenharia institucional, em que os partidos têm apenas a obrigação de inserirem as mulheres na competição, de forma desinteressada em distribuir oportunidades e recursos financeiros (JUNCKES et al., 2015; SILVA et al., 2017; PEIXOTO; SILVA, 2018).

Embora se tenha alguns esforços garantidos por lei para que haja maior participação da mulher, estes não tem sido suficiente para garantir uma democracia paritária (MIGUEL, 2000; ARAÚJO; ALVES, 2007; BOLOGNESI, 2012; SACCHET, 2018).

Outro ponto chave para se compreender a representação política é o financiamento eleitoral e estes são indissociáveis. As questões que envolvem dinheiro e política vão desde afetar as normas da democracia, em aspectos de igualdade na disputa e as chances de vitória de um candidato, até sua atuação legislativa, quanto maior for a capacidade de mobilização de recursos, maior a chance de ser eleito e de acessar uma rede de doadores, sendo decisivo para o sucesso da arrecadação (SILVA; CERVI, 2017; CARLOMAGNO; CODATO, 2018).

Em sua pesquisa sobre o financiamento empresarial entre as eleições de 1994 a 2014, Speck (2016) além de sinalizar a concentração do financiamento empresarial em poucos candidatos, o que teria relação com o seu desempenho eleitoral, também apontou a desigualdade da participação entre as empresas, apenas 100 concentravam 57\% dos recursos doados, criando a imagem da democracia brasileira como plutocracia.

O trabalho de Junckes et al. (2019), sobre a rede de financiamento nas eleições de 2014, evidenciaram que candidatos que não têm pelo menos dois doadores têm suas chances de se eleger reduzidas a quase zero, revelando que apenas 5,6\% das pessoas físicas e 21,9\% das pessoas jurídicas influenciaram quase que a totalidade dos eleitos de 2014, o que Mancuso (2015) destaca como um agravante que afeta valores democráticos, como igualdade política e a competição política. 
BUENO, A. A. M.; JUNCKES, I. J. Dinheiro, democracia e a (sub) representação das mulheres nas eleições de 2008, 2012 e 2016 no Brasil. DOI: http://dx.doi.org/10.5380/recp.v11i2.81598

Adicionalmente, a experiência política, reeleição, capital social e acesso às redes estratégicas estão associados ao sucesso eleitoral e a maiores arrecadações de contribuições de pessoas jurídicas nas campanhas dos candidatos. A explicação estaria na preferência dos doadores em investir em candidatos que já tenham um histórico eleitoral, o que daria a eles maior visibilidade, tanto para maximizar a probabilidade de investir em candidaturas vencedoras ou para recompensar os candidatos onde o desempenho anterior tenha sido bem avaliado (SACCHET; SPECK, 2010; CODATO; CERVI; PERISSINOTTO, 2013; SILVA; CERVI, 2017; MANCUSO; HOROCHOVSKI; CAMARGO, 2018).

Carlomagno e Codato (2018) também apontaram que a posição social dos candidatos como determinantes para o acesso às redes de financiamento, destacando que quando ocupam a mesma posição social, as desigualdades de sexo desaparecem.

A partir de 2015 as regras para o financiamento eleitoral sofreram uma grande modificação com a proibição das doações de empresas. A partir de uma Ação Direta de Inconstitucionalidade (ADI), interposta pela Ordem dos Advogados do Brasil (OAB), o Supremo Tribunal Federal tornou inconstitucional o financiamento empresarial, considerando legais apenas as doações de pessoas físicas, recursos dos próprios candidatos e dos fundos partidários ou eleitorais. O julgamento da ADI teve como momento chave o voto do ministro-relator Luiz Fux, que atendia integralmente aos argumentos para tornar a disputa política menos desigual, considerando que o sucesso eleitoral estava fortemente relacionado a campanhas caras, tornando a política dependente do valor econômico (MANCUSO; SPECK, 2014).

A questão é: a fonte dos recursos empresariais era a única a provocar desigualdades no financiamento eleitoral? Quais seriam as "soluções" que os partidos encontrariam para viabilizar as campanhas sem os recursos empresariais?

Analisando os principais atores do financiamento eleitoral (pessoas jurídicas; pessoas físicas; partidos políticos; outros candidatos e partidos; recursos dos próprios candidatos) nas eleições de 2014 para deputados federais, Silva (2016) revela que da mesma forma que as empresas tinham um papel importante no financiamento eleitoral no Brasil, o autofinanciamento e as doações de pessoas físicas ajudam a agravar a distorção das condições de disputa.

A proibição do financiamento empresarial talvez não implique grandes mudanças para as mulheres, por já se encontrarem em situação de “esquecidas" pelos financiadores. Partindo da análise de Silva (2016) pode ser que se tenha um quadro em que apenas aquelas que tenham poder de se autofinanciar consigam garantir seu espaço nesse cenário, não trazendo mudanças para o quadro atual de exclusão e marginalização da participação da mulher na política. 
BUENO, A. A. M.; JUNCKES, I. J. Dinheiro, democracia e a (sub) representação das mulheres nas eleições de 2008, 2012 e 2016 no Brasil. DOI: http://dx.doi.org/10.5380/recp.v11i2.81598

Diante disso, com o objetivo de contribuir com os debates anteriormente expostos, no próximo tópico trata-se da apresentação e discussão dos resultados da participação das mulheres nas eleições.

\section{APRESENTAÇÃO E DISCUSSÃO DOS RESULTADOS}

O intuito deste primeiro tratamento de dados, foi verificar a participação relativa das mulheres entre as candidaturas que naufragam após o registro, ou seja, daquelas tornadas inaptas pelos tribunais eleitorais e explicar minimamente este fenômeno. Em seguida, realizou-se a análise do desempenho eleitoral das mulheres e finalmente a análise do sucesso eleitoral entre homens e mulheres.

\subsection{CANDIDATURAS INAPTAS}

Sinaliza-se a importância de se diferenciar candidaturas registradas e aquelas que efetivamente participam do pleito eleitoral, pois, entre o registro formal e o dia das eleições há um longo caminho que exige apoio burocrático e dinheiro para o desenvolvimento inicial da campanha. Para aquelas que rompem com as barreiras e decidem participar, existe um caminho desde a formalização da candidatura pelo partido político junto aos tribunais eleitorais, recebendo-se a situação de deferido ou indeferido, até a candidatura se tornar apta para participar do processo eleitoral. Após ter solicitado o registro de candidatura há de se investigar quantas efetivamente chegaram a estar presentes na urna, ou seja, quais delas foram consideradas aptas e se a diferença entre sexos é estatisticamente significativa. A Tabela 1 exibe os resultados.

Tabela 1 - Situação das candidaturas a vereador nos municípios com mais de 50 mil eleitores por eleição

\begin{tabular}{|c|c|c|c|c|c|c|c|c|c|c|c|c|c|}
\hline \multirow{4}{*}{ Variáveis } & \multicolumn{13}{|c|}{ Situação das candidaturas } \\
\hline & \multicolumn{4}{|c|}{2008} & \multicolumn{4}{|c|}{2012} & \multicolumn{4}{|c|}{2016} & \multirow{3}{*}{$\frac{\mathrm{p} \text {-valor }}{<0,001^{*}}$} \\
\hline & \multicolumn{2}{|c|}{ Apta } & \multicolumn{2}{|c|}{ Inapta } & \multicolumn{2}{|c|}{ Apta } & \multicolumn{2}{|c|}{ Inapta } & \multicolumn{2}{|c|}{ Apta } & \multicolumn{2}{|c|}{ Inapta } & \\
\hline & $\mathbf{N}$ & $\%$ & $\mathbf{N}$ & $\%$ & $\mathbf{N}$ & $\%$ & $\mathbf{N}$ & $\%$ & $\mathbf{N}$ & $\%$ & $\mathbf{N}$ & $\%$ & \\
\hline \multicolumn{14}{|l|}{ Sexo } \\
\hline Feminino & 18.702 & 91,3 & 1.790 & 8,7 & 34.491 & 87,5 & 4.917 & 12,5 & 38.764 & 91,2 & 3.734 & 8,8 & \\
\hline Masculino & 60.718 & 93,4 & 4.281 & 6,6 & 78.997 & 92,4 & 6.499 & 7,6 & 85.435 & 94,6 & 49.02 & 5,4 & \\
\hline
\end{tabular}

*Apresenta significância estatística ( $\mathrm{p}$-valor $<0,05)$ no teste qui-quadrado de associação em todos os anos. Fonte: Dados do TSE organizados pelos autores (2020).

O teste qui-quadrado possibilitou verificar que as diferenças de percentuais foram significativas, o p-valor revelou que há associação estatisticamente significativa entre as variáveis analisadas "sexo dos candidatos" e "candidaturas aptas ou não". Nos três ciclos eleitorais podemos 
BUENO, A. A. M.; JUNCKES, I. J. Dinheiro, democracia e a (sub) representação das mulheres nas eleições de 2008, 2012 e 2016 no Brasil. DOI: http://dx.doi.org/10.5380/recp.v11i2.81598

verificar que aproximadamente uma a cada dez candidaturas de mulheres inscritas não chega às urnas, enquanto entre os homens essa razão é de aproximadamente um para cada quinze. Conforme mencionado anteriormente, a não representação das mulheres vai de encontro com as condições proporcionadas pelos partidos, as quais, não tem sido favoráveis para as mulheres.

Partindo da literatura (PERISSINOTTO; MIRÍADE, 2009; SPECK; SACCHET, 2012), foram testadas as variáveis como grau de instrução e ocupação dos candidatos, tais características geram desigualdades na competição política, pois se constituem como atributo chave para acessar os postos de elite na democracia ocidental. Além dessas variáveis, atributos institucionais como ser candidato à reeleição (incumbentes) e ter constituído uma carreira política também foram testadas. A receita declarada pelos candidatos para viabilizar a campanha foi outro fator a ser considerado.

As variáveis foram testadas com o objetivo de verificar se tinham associação com a inaptidão entre as mulheres, podendo ser verificado na Tabela 2:

Tabela 2 - associação das variáveis qualitativas com a situação da candidatura(apta/inapta)

\begin{tabular}{|c|c|c|c|c|c|c|c|}
\hline \multirow{3}{*}{ Variáveis } & \multicolumn{6}{|c|}{ Candidaturas femininas aptas/ inaptas (\%) (continua) } & \multirow[b]{3}{*}{$\mathrm{p}$-valor } \\
\hline & \multicolumn{2}{|l|}{2008} & \multicolumn{2}{|l|}{2012} & \multicolumn{2}{|l|}{2016} & \\
\hline & Inapta & Apta & Inapta & Apta & Inapta & Apta & \\
\hline Grau de Instrução & & & & & & & $<0,001 *$ \\
\hline Fundamental & 24,4 & 20,5 & 24,7 & 21,6 & 24,2 & 20,5 & \\
\hline Médio & 41,3 & 38,2 & 46,1 & 42,5 & 45,8 & 43,3 & \\
\hline Superior & 34,3 & 41,3 & 29,2 & 35,9 & 30,0 & 36,2 & \\
\hline Ocupação & & & & & & & $<0,001 *$ \\
\hline $\begin{array}{c}\text { Não especializado }+ \\
\text { Especializado } \\
\text { fundamental }\end{array}$ & 39,2 & 35,7 & 42,6 & 38,1 & 42,8 & 38,3 & \\
\hline $\begin{array}{l}\text { Especializado médio }+ \\
\text { Especializado superior }\end{array}$ & 60,8 & 64,2 & 57,4 & 61,9 & 57,1 & 61,7 & \\
\hline Carreira política & & & & & & & $<0,001 *$ \\
\hline $\begin{array}{l}\text { Não político de } \\
\text { carreira }\end{array}$ & 99,6 & 98,3 & 99,7 & 99,1 & 99,7 & 98,9 & \\
\hline Político de carreira & 0,4 & 1,7 & 0,3 & 0,9 & 0,3 & 1,1 & \\
\hline Incumbente & & & & & & & $<0,001^{*}$ \\
\hline Desafiante & 99,3 & 97,4 & 99,6 & 98,7 & 99,7 & 98,5 & \\
\hline Incumbente & 0,7 & 2,6 & 0,4 & 1,3 & 0,3 & 1,5 & \\
\hline Receitas & 1,5 & 98,5 & 1,7 & 98,3 & 2,2 & 97,8 & $<0,001 *$ \\
\hline
\end{tabular}

*Apresenta significância estatística ( $\mathrm{p}$-valo $\mathrm{r}<0,05)$ no teste qui-quadrado de associação em todos os anos. Fonte: Dados do TSE organizados pelos autores (2020).

O teste do qui-quadrado $(\mathrm{p}<0,001)$ evidencia associação forte e positiva entre as variáveis testadas e ter sua candidatura apta ou não, os dados revelam que as mulheres são mais afetadas pela inaptidão de suas candidaturas que os homens e que essas mulheres tendem a apresentar grau de 
BUENO, A. A. M.; JUNCKES, I. J. Dinheiro, democracia e a (sub) representação das mulheres nas eleições de 2008, 2012 e 2016 no Brasil. DOI: http://dx.doi.org/10.5380/recp.v11i2.81598

instrução menor, ocupação não especializada ou baixa especialização, escassos recursos de campanha, condição de desafiantes ou sem carreira política. Sob estas condições, as mulheres iniciam a construção de uma carreira política.

Diante disso, com possíveis fatores explicativos para os não candidatos, se avança nos estudos sobre os candidatos que se tornaram elegíveis para disputa eleitoral, assim, no tópico seguinte analisa-se a relação entre os votos recebidos e as receitas investidas em campanhas.

\subsection{FINANCIAMENTO E DESEMPENHO ELEITORAL}

Como o financiamento de campanhas se tornou um dos temas mais estudados da ciência política, buscou-se identificar a influência dos recursos financeiros nos resultados das eleições municipais estudadas. Dessa forma, explorou-se inicialmente a correlação entre o dinheiro investido nas campanhas e os votos recebidos. A Tabela 3 a seguir possibilita uma primeira aproximação com a dimensão dos números trabalhados a partir dos 441 municípios com mais de 50 mil eleitores:

Tabela 3 - Candidaturas aptas e receitas de campanha, para o cargo de vereador, nos municípios com mais de 50 mil eleitores, por eleição

\begin{tabular}{ccc}
\hline Ano eleitoral & $\mathrm{N}$ & Receitas $^{6}$ \\
\hline 2008 & 79.420 & $\mathrm{R} \$ 871.500 .638,00$ \\
2012 & 113.488 & $\mathrm{R} \$ 1.280 .946 .380,00$ \\
2016 & 124.199 & $\mathrm{R} \$ 713.610 .098,00$ \\
\hline
\end{tabular}

Fonte: Dados do TSE organizados pelos autores (2020).

As eleições de 2016 apresentaram um volume de receitas menor, em relação as eleições do ano anterior representaram um pouco mais da metade (56\%) dos recursos investidos em 2012. Ao analisar um volume menor de receitas no ano de 2016, poder-se-ia sugerir que, com uma campanha "mais barata", as regras do jogo se tornaram menos desiguais, e que as chances de um candidato que possui menos recursos poderia aumentar, especialmente no caso das mulheres.

Em sua pesquisa, Deschamps (2019) verificou que o montante de receitas das mesmas eleições, com o mesmo recorte de municípios, estava associado ao desempenho dos candidatos, indicando que as duas variáveis estavam correlacionadas. O coeficiente de correlação de Pearson ${ }^{7}$, indicou em todos os anos $(2008-0,67 ; 2012-0,66 ; 2016-0,69)^{8}$ uma correlação forte entre o

6 Os valores de receitas de campanha das duas primeiras eleições foram atualizados para outubro de 2016 pelo Índice de Preços ao Consumidor Amplo (IPCA) obtido no endereço eletrônico: "https://www3.bcb.gov.br/CALCIDADAO/publico/corrigirPorIndice.do?method=corrigirPorIndice".

7 O coeficiente de correlação Pearson (r) varia de -1 a 1. O sinal indica direção positiva ou negativa do relacionamento e o valor sugere a força da relação entre as variáveis. Sobre a magnitude dos coeficientes, Cohen (1998) apresenta a seguinte classificação: $0,10<\mathrm{r}<0,29=$ pequeno; $0,30<\mathrm{r}<0,49=$ médio e $\mathrm{r}>0,50=$ grande. (FIGUEIREDO FILHO; SILVA JÚNIOR, 2009).

8 Resultados dos valores relativos. 
BUENO, A. A. M.; JUNCKES, I. J. Dinheiro, democracia e a (sub) representação das mulheres nas eleições de 2008, 2012 e 2016 no Brasil. DOI: http://dx.doi.org/10.5380/recp.v11i2.81598

financiamento eleitoral e o total de votos recebido. Sinalizando que, mesmo com menos dinheiro investido em 2016, visto a proibição do financiamento empresarial, a campanha de 2016 não mostrou diferença entre os outros anos e teve grande influência dos recursos financeiros.

Partindo desses resultados, em que a relação entre dinheiro e voto foi determinante para o desempenho eleitoral, pretendeu-se investigar se essa relação apresenta diferenças entre homens e mulheres. Pela magnitude dos distritos e a amplitude dos valores e do número de votos recebidos pelos candidatos, estes foram normalizados por meio de um índice para a variável independente receita $(\text { PCRM })^{9}$ e para a variável dependente total de votos $(\text { PCVM })^{10}$. A Tabela abaixo apresenta a análise de regressão:

Tabela 4 - Análise de regressão linear simples para a quantidade de votos e receitas por sexo (pcrm x pcrm)

\begin{tabular}{ccccccc}
\hline $\begin{array}{c}\text { Ano } \\
\text { eleitoral }\end{array}$ & Sexo & Coeficiente $^{\mathrm{b}}$ & $\mathrm{p}^{\text {-valor }}{ }^{\mathrm{a}}$ & $\mathrm{R}$ & $\mathrm{R}^{2}(\%)$ & $\mathrm{p}^{\text {-valor }}{ }^{\mathrm{b}}$ \\
\hline \multirow{2}{*}{2008} & Feminino & 0,46718 & $<0,001^{*}$ & 0,702 & $49 \%$ & $<0,001^{*}$ \\
& Masculino & 0,47617 & $<0,001^{*}$ & 0,67 & $45 \%$ & $<0,001^{*}$ \\
\hline \multirow{2}{*}{2012} & Feminino & 0,444 & $<0,001^{*}$ & 0,646 & $42 \%$ & $<0,001^{*}$ \\
& Masculino & 0,4728 & $<0,001^{*}$ & 0,662 & $44 \%$ & $<0,001^{*}$ \\
\hline \multirow{2}{*}{2016} & Feminino & 0,535 & $<0,001^{*}$ & 0,696 & $49 \%$ & $<0,001^{*}$ \\
& Masculino & 0,54717 & $<0,001^{*}$ & 0,691 & $48 \%$ & $<0,001^{*}$ \\
\hline
\end{tabular}

*Apresenta significância estatística ( $\mathrm{p}$-valor $<0,05)$, coeficiente ${ }^{\mathrm{b}}$ coeficiente da variável explicativa no modelo de regressão bruta (simples), $\mathrm{R}^{2}$ coeficiente de explicação da regressão, $\mathrm{p}$-valor ${ }^{\mathrm{a}}$ refere-se a significância do coeficiente da variável explicativa, $\mathrm{p}$-valor ${ }^{\mathrm{b}}$ refere-se a significância da regressão, teste $\mathrm{F}$.

Fonte: Dados do TSE organizados pelos autores (2020).

Em todos os anos, os candidatos homens tiveram um aumento nos votos em comparação com as mulheres, respectivamente em 2008 0,47617; em 2012 0,4728 e em 2016 0,54717. Além disso, o coeficiente de Pearson apresentou maior elevação para as mulheres em 2008 e 2016, o R² também foi um pouco mais significativo para as mulheres do que para os homens. O dinheiro demonstrou ser importante tanto para candidaturas masculinas quanto para as femininas.

Visto que a relação entre dinheiro e desempenho é forte tanto entre mulheres quanto entre os homens, torna-se muito importante investigar a distribuição da receita entre candidaturas masculinas e candidaturas femininas e o desempenho e o sucesso eleitoral. Para esse fim, foram realizados testes “ $t$ " para as médias. Os resultados estão dispostos na Tabela 5 a seguir:

9 R Candidato é igual ao total de receitas do candidato e $\mathrm{R}$ Munícipio é igual ao total de receitas dos candidatos no distrito/ município.

$10 \mathrm{~V}$ Candidato é igual ao total de votos do candidato e V Munícipio é igual ao total de votos dos candidatos no distrito/ município 
BUENO, A. A. M.; JUNCKES, I. J. Dinheiro, democracia e a (sub) representação das mulberes nas eleições de 2008, 2012 e 2016 no Brasil. DOI: http:/ / dx.doi.org/10.5380/recp.v11i2.81598

Tabela 5 - Receita média de campanha e votos por sexo (distribuição das medidas centrais)

\begin{tabular}{|c|c|c|c|c|c|c|}
\hline \multirow[b]{3}{*}{$\begin{array}{l}\text { Ano } \\
\text { eleitoral }\end{array}$} & \multirow[b]{3}{*}{ Variáveis } & \multicolumn{4}{|c|}{ Sexo } & \multirow[b]{3}{*}{$\mathrm{p}$-valor } \\
\hline & & \multicolumn{2}{|c|}{ Masculino } & \multicolumn{2}{|c|}{ Feminino } & \\
\hline & & Média & Mediana & Média & Mediana & \\
\hline \multirow{2}{*}{2008} & Receitas & 12.053 & 2.877 & 7.467 & 1.748 & $<.001^{* *}$ \\
\hline & Votos & 727 & 314 & 369 & 126 & $<.001 * *$ \\
\hline \multirow{2}{*}{2012} & Receitas & 13.438 & 3.010 & 6.361 & 1.148 & $<.001^{* *}$ \\
\hline & Votos & 595 & 232 & 227 & 61 & $<.001 * *$ \\
\hline \multirow{2}{*}{2016} & Receitas & 6.839 & 1.830 & 3.336 & 905 & $<.001^{* *}$ \\
\hline & Votos & 552 & 216 & 216 & 60 & $<.001^{* *}$ \\
\hline
\end{tabular}

*Apresenta significância estatística ( $\mathrm{p}$-valor $<0,05)$ no teste de comparação de médias - teste $\mathrm{t}$. ${ }^{*}$ Apresenta significância estatística ( $\mathrm{p}$-valor $<0,05)$ no teste Mann-Whitney U.

Fonte: Dados do TSE organizados pelos autores (2020).

Para receitas e votos, as mulheres apresentaram valores inferiores quando comparadas aos homens. Destaca-se que a média de receita das mulheres em todos os anos é quase $50 \%$ menor que a dos homens, o valor de p nos mostra que as diferenças de médias dos dois grupos são maiores que as esperadas pela chance ou pelo acaso, existe uma diferença estatisticamente significativa entre os dois grupos avaliados.

A dinâmica plutocrática, poderia, ou deveria segundo a expectativa normativa, ter sofrido mudanças com a proibição do financiamento empresarial nas eleições de 2016. Os dados indicam a necessidade de estudos sobre o alcance do autofinanciamento e dos mecanismos de distribuição dos recursos financeiros no interior dos partidos políticos, marcadamente dominados por direções centralizadas e centralizadoras compostos em sua absoluta maioria por homens (ARAÚJO, 2005; CERVI; BORBA, 2019).

Por fim, tendo em vista a intensidade da correlação entre receita e votos, a partir dos testes estatísticos aplicados, pode-se afirmar que mulheres recebem relativamente menos votos que os homens porque recebem menos receita, visto que a força explicativa das receitas para o voto é maior entre as mulheres que entre os homens. Não se pode afirmar que o simples incremento de recursos financeiros para as candidatas as colocaria em melhores condições de desempenho, porém, a partir dos dados apresentados, afirma-se que a persistência de mulheres entre aqueles candidatos que recebem as menores médias de recursos as condena ao grupo que recebe menos votos, e, portanto, com menores condições de obter o sucesso eleitoral e figurar entre os eleitos, os quais são o objeto de investigação relatado no próximo tópico. 
BUENO, A. A. M.; JUNCKES, I. J. Dinheiro, democracia e a (sub) representação das mulheres nas eleições de 2008, 2012 e 2016 no Brasil. DOI: http://dx.doi.org/10.5380/recp.v11i2.81598

\subsection{SUCESSO ELEITORAL: VARIÁVEIS EXPLICATIVAS}

No tópico anterior demonstrou-se que mais receita implica mais votos, favorecendo especialmente os homens, que por acumularem mais receitas obtém mais votos. Todavia nem sempre os mais votados são os eleitos. A primeira questão a ser respondida é, portanto, se os eleitos apresentam receitas superiores aos não eleitos, ou seja, verifica-se isto testando a média entre ambos os grupos conforme a Tabela abaixo:

Tabela 6 - Comparação de médias de receitas (r\$) entre eleitos(as) e não eleitos

\begin{tabular}{cccccc}
\hline & \multicolumn{5}{c}{ Resultado da eleição } \\
\cline { 2 - 6 } Ano & Não eleito & \multicolumn{3}{c}{ Eleito } \\
\cline { 2 - 6 } eleitoral & Média & Md & Média & Md & P-valor \\
2008 & $7.573,00$ & $2.164,00$ & $55.216,00$ & $24.934,00$ & $<.001^{* *}$ \\
2012 & $7.794,00$ & $1.937,00$ & $61.188,00$ & $26.308,00$ & $<.001^{* *}$ \\
2016 & $4.091,00$ & $1.299,00$ & $31.258,00$ & $16.238,00$ & $<.001^{* *}$ \\
\hline
\end{tabular}

$* \overline{\text { Apresenta significância estatística (p-valor }<0,05) \text { no teste de comparação de médias - teste t. }{ }^{* *} \text { Apresenta significância }}$ estatística (p-valor $<0,05)$ no teste Mann-Whitney U.

Fonte: Dados do TSE organizados pelos autores (2020).

O teste de comparação de médias (teste t) revelou que as diferenças entre as receitas de eleitos e não eleitos são estatisticamente significativas, os dados revelam que nas três eleições os eleitos apresentaram médias de receitas quase oito vezes a mais que os não eleitos. Uma vez que os homens apresentam as maiores receitas e o maior desempenho eleitoral, medido pela votação, implica-se em verificar se homens apresentam sucesso eleitoral superior ao das mulheres nos pleitos pesquisados.

Como no quartil superior de receitas encontra-se maior concentração de eleitos e receitas (mais de $83 \%$ em todas as eleições), verificou-se a relação entre receita e sucesso eleitoral entre as mulheres, a Tabela 7 a seguir apresenta uma comparação dos quartis superiores da distribuição das receitas por sexo, constando nas tabelas somente os eleitos.

Tabela 7 - Quartil superior receitas candidatos e candidatas eleitos (as) nas eleições de 2008,

\begin{tabular}{|c|c|c|c|c|c|c|c|}
\hline \multirow{3}{*}{ Variáveis } & \multicolumn{6}{|c|}{ Ano da eleição } & \multirow[b]{3}{*}{ p-valor } \\
\hline & \multicolumn{2}{|c|}{2008} & \multicolumn{2}{|c|}{2012} & \multicolumn{2}{|c|}{2016} & \\
\hline & Eleitos (\%) & Receitas (\%) & Eleitos $(\%)$ & Receitas (\%) & Eleitos $(\%)$ & Receitas (\%) & \\
\hline Sexo & & & & & & & $>0,05^{*}$ \\
\hline Masculino & 0,89 & 0,88 & 0,89 & 0,88 & 0,89 & 0,88 & \\
\hline Feminino & 0,11 & 0,12 & 0,11 & 0,12 & 0,11 & 0,12 & \\
\hline
\end{tabular}

*Não apresenta significância estatística (p-valor $>0,05)$ no teste de comparação de médias - teste t.

Fonte: Dados do TSE organizados pelos autores (2020). 
Analisando a diferença das médias de receitas de homens e mulheres eleitos (as) no quartil superior, percebe-se que as diferenças não são significativas ( $\mathrm{p}$-valor maiores que 0,05 ). Em todos os anos, no quartil superior de receitas, as mulheres participam com $12 \%$ das receitas e $11 \%$ dos eleitos, ou seja, as mulheres fazem corresponder receita ao sucesso eleitoral, tanto quanto os homens. Ou seja, indicativamente, se elas tivessem mais receitas teriam mais sucesso eleitoral, sem qualquer desconsideração com outras variáveis que contribuem para a explicação da subrepresentação das mulheres na política.

No tópico seguinte, pretendeu-se investigar quais atributos estariam associados e qual a sua influência na arrecadação de recursos financeiros pelas candidatas ao cargo de vereadora.

\subsection{ATRIBUTOS E ARRECADAÇÃO DE RECURSOS FINANCEIROS DE HOMENS E}

\section{MULHERES}

Identificar fatores que influenciam na arrecadação de receitas possibilita a indicação de políticas públicas que ampliem a participação das mulheres na política eleitoral. É neste sentido que se organizou o presente tópico de apresentação e discussão dos resultados da pesquisa. Inicialmente, investigou-se quais os atributos registrados pelos candidatos aptos influenciam a arrecadação. Para tanto, realizou-se a distribuição das variáveis com a estratificação em quartis de receita aplicados nas campanhas de 2008, 2012 e 2016. Em todos os anos ocorre diferença em todas as variáveis quando associadas aos quartis de receita declaradas pelos candidatos. O Gráfico 1 a seguir evidencia essa dinâmica.

Gráfico 1 - Participação por gênero nos quartis de receita de campanha por eleição

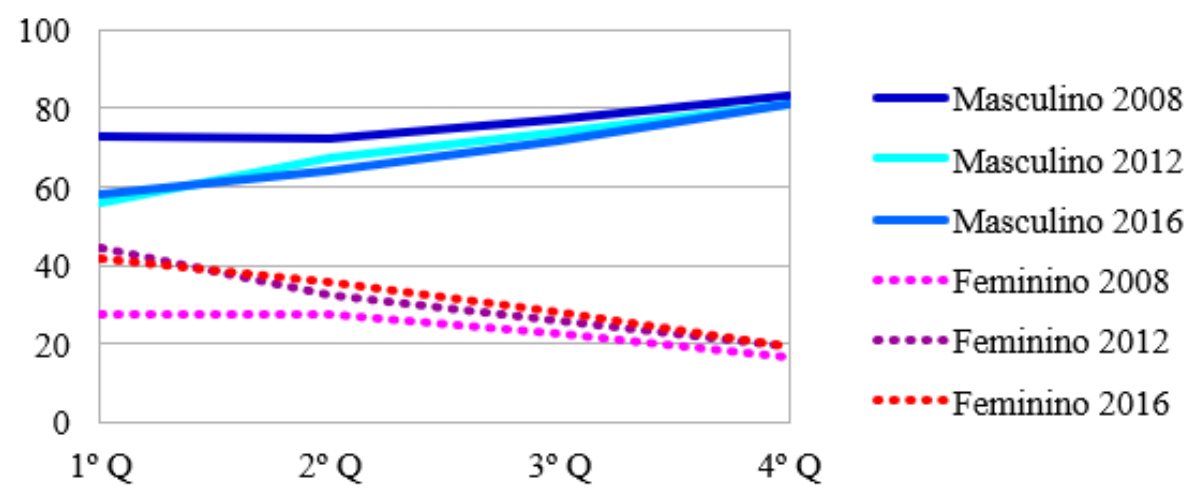

Fonte: Dados do TSE organizados pelos autores (2020).

O gráfico demonstra que, conforme aumentam os quartis de receitas, há predominância de candidatos homens. Em todos os anos eles representaram mais de $80 \%$ no quartil mais alto. No caso das mulheres ocorre o inverso, a maior concentração de mulheres se encontra nos quartis mais baixos de receitas. Quando comparadas as proporções de candidatas por quartil, em 2012 e 
BUENO, A. A. M.; JUNCKES, I. J. Dinheiro, democracia e a (sub) representação das mulheres nas eleições de 2008, 2012 e 2016 no Brasil. DOI: http://dx.doi.org/10.5380/recp.v11i2.81598

2016 elas representaram mais de 40\% no quartil mais baixo de receitas, em 2008 a maioria ficou no segundo quartil mais baixo, sendo possível observar a redução da participação de mulheres conforme os quartis aumentam em relação a maior receita.

Destaca-se também o aumento na quantidade de candidatos com ensino superior e casados, conforme os quartis indicam maiores valores de receitas e distribuição de votos. Ainda, as maiores porcentagens de políticos de carreiras e incumbentes estavam entre os candidatos com mais altos valores de receita.

Além de evidenciar a acentuada redução da participação das mulheres nos quartis com maior receita, a pesquisa em tela confirma o que apontaram Mancuso, Horochovski e Camargo (2018), em que os candidatos mais escolarizados seriam vistos pelos financiadores como mais preparados para o trabalho da representação política.

Conforme realizado anteriormente, pela concentração de eleitos e receitas, se retorna à análise para o quartil superior de receitas apenas com as candidatas e candidatos eleitos, verificando a associação entre o sucesso eleitoral e as variáveis qualitativas, conforme demonstrado na Tabela abaixo:

Tabela 8 - Associação entre resultado da eleição no quartil superior de receita e variáveis qualitativas por eleição

\begin{tabular}{|c|c|c|c|c|c|c|c|}
\hline \multirow{3}{*}{ Variáveis } & \multicolumn{6}{|c|}{ Eleitos (as) Quartil Superior de Receitas (\%) } & \multirow[b]{3}{*}{$\mathrm{p}$-valor } \\
\hline & \multicolumn{2}{|c|}{2008} & \multicolumn{2}{|c|}{2012} & \multicolumn{2}{|c|}{2016} & \\
\hline & Feminino & Masculino & Feminino & Masculino & Feminino & Masculino & \\
\hline Grau de Instrução & & & & & & & $<.001^{*}$ \\
\hline Fundamental & 5,4 & 14,9 & 4,8 & 13,8 & 6,1 & 13,0 & \\
\hline Médio & 18,9 & 30,2 & 21,5 & 33,8 & 20,6 & 35,2 & \\
\hline Superior & 75,7 & 54,8 & 73,6 & 52,4 & 73,3 & 51,9 & \\
\hline Ocupação & & & & & & & $<.001 *$ \\
\hline Não especializado & 2,7 & 0,7 & 3,6 & 0,7 & 3,3 & 0,7 & \\
\hline $\begin{array}{l}\text { Especializado } \\
\text { fundamental }\end{array}$ & 8,3 & 24,6 & 8,4 & 22,1 & 9,7 & 21,1 & \\
\hline Especializado médio & 16,6 & 25,2 & 17,0 & 28,4 & 17,8 & 29,6 & \\
\hline Especializado superior & 72,4 & 49,6 & 70,9 & 48,8 & 69,1 & 48,6 & \\
\hline Carreira política & & & & & & & $\begin{array}{c}<.001^{* ;} ;> \\
0,05^{* *}\end{array}$ \\
\hline $\begin{array}{l}\text { Não 111olitico de } \\
\text { carreira }\end{array}$ & 73,6 & 73,4 & 76,4 & 74,0 & 74,5 & 69,7 & \\
\hline Político de carreira & 26,4 & 26,6 & 23,6 & 26,0 & 25,5 & 30,3 & \\
\hline Incumbente & & & & & & & $\begin{array}{c}<.001^{*} ;> \\
0,05^{* *}\end{array}$ \\
\hline Desafiante & 57,9 & 53,6 & 64,8 & 61,1 & 58,5 & 53,1 & \\
\hline Incumbente & 42,1 & 46,4 & 35,2 & 38,9 & 41,5 & 46,9 & \\
\hline
\end{tabular}


Os testes demonstram que nas três eleições, tanto candidatos eleitos como candidatas eleitas nesse quartil, tendem a ser mais escolarizados e a ocuparem cargos profissionais mais elevados, entretanto, as mulheres eleitas no quartil superior de receitas apresentam grau de escolaridade e de ocupação maiores do que a dos homens (superiores a 70\%). A maioria dos homens eleitos nesse quartil também apresentaram grau de escolaridade superior, porém não na mesma proporção que as mulheres. Os dados revelam que os candidatos homens conseguem se eleger com graus de escolaridade e ocupação mais baixos.

A partir dos dados, pelo quantitativo de homens que conseguem se eleger com instruções mais baixas, e pelo teste de associação percebe-se que a valorização social dada à instrução formal "pesa" mais para o gênero feminino. Tal exigência está associada e pode ser indicativamente confirmada na distribuição de ocupação declarada pelos eleitos e pelas diferenças da distribuição entre homens e mulheres.

Para o grupo das mulheres há uma exigência em se superqualificarem. Pontua-se que, mesmo que se apresente um perfil de mulheres na elite política, quando comparado aos homens, a posição social delas a partir dos cargos que ocupam tem maior influência na decisão eleitoral do que para eles.

Para as duas variáveis testadas (carreira política e condição de desafiante ou incumbente), com exceção das eleições de 2016, o sexo dos candidatos não apresentou influência, o êxito eleitoral de homens e mulheres com carreira política e incumbentes mostram resultados similares no quartil superior de receitas. Para os anos de 2008 e 2012, significa dizer que independente do sexo dos candidatos, quando se possui uma carreira política e está na condição de incumbente, as chances de eleição são as mesmas. Em 2016, o fato de ser mulher teve influência no resultado da eleição, mesmo apresentando as mesmas características políticas, os homens tiveram maior probabilidade de ser eleitos do que as mulheres, o que pode ser um indicativo de aumento das desigualdades.

Buscando entender o que aumenta ou diminui a probabilidade do sucesso eleitoral realizouse análise de regressão logística aplicada nas variáveis qualitativas. Na Tabela a seguir, apresenta-se resultados da análise de regressão logística univariada das variáveis independentes selecionadas em relação ao sucesso nas eleições de 2008, 2012 e 2016. 
BUENO, A. A. M.; JUNCKES, I. J. Dinheiro, democracia e a (sub) representação das mulheres nas eleições de 2008, 2012 e 2016 no Brasil. DOI: http:/ /dx.doi.org/10.5380/recp.v11i2.81598

Tabela 9 - Análise de regressão logística univariada das variáveis qualitativas em relação ao resultado da eleição

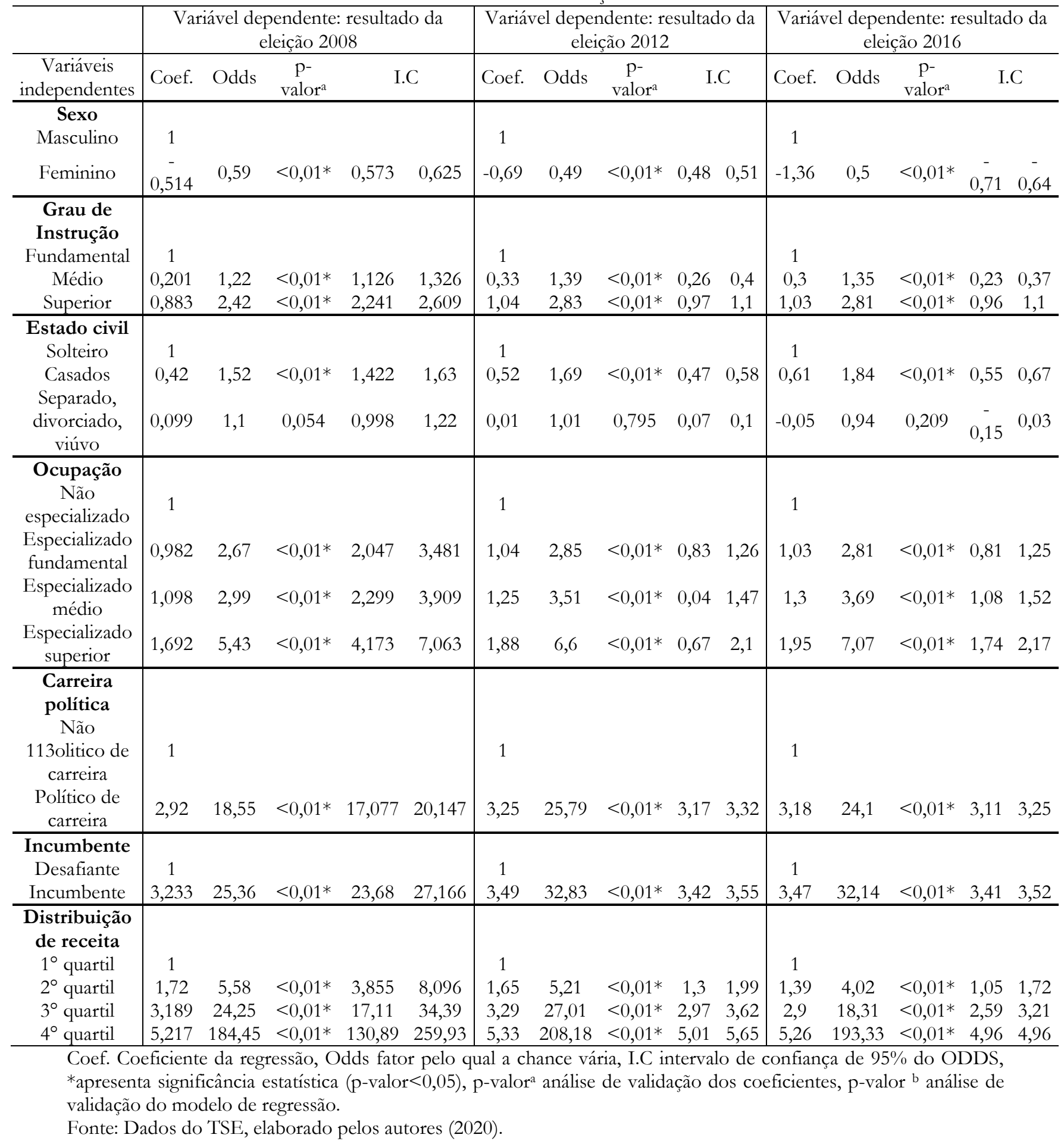

Em todas as eleições, os resultados das análises de regressão logísticas simples indicam que ser mulher diminui a probabilidade de ser eleito. Em 2008 houve uma diminuição das chances em quase $40 \%$ e para os anos seguintes, a condição de ser mulher piorou as chances de eleição, elas tiveram metade das chances de um homem, evidência já esperada. 
BUENO, A. A. M.; JUNCKES, I. J. Dinheiro, democracia e a (sub) representação das mulheres nas eleiçöes de 2008, 2012 e 2016 no Brasil. DOI: http://dx.doi.org/10.5380/recp.v11i2.81598

Sobre os fatores que aumentaram a probabilidade de eleição, destaca-se que a receita afeta sobremaneira o resultado das eleições, os candidatos enquadrados no quartil mais alto de receita, ou seja, aqueles que aplicaram mais receitas em sua campanha, apresentaram mais de 184 vezes mais chances em de serem eleitos em todos os anos, em relação aos concorrentes do quartil inferior de receita.

Seguido da receita, ser político de carreira ou incumbente foram características que elevaram muito a probabilidade de ser eleito. Em 2008 ser político de carreira gerou um aumento de 18 vezes mais chances que os candidatos inexperientes, em 2012 e 2016 gerou um aumento de 20 vezes mais chances de ser eleito. Os candidatos incumbentes, em 2008 tiveram quase 26 vezes mais chances em relação aos desafiantes, em 2012 e 2016 o aumento foi de 30 vezes mais. Fatores como a ocupação e o grau de instrução também elevaram as chances de eleição em relação à níveis menores de escolaridade e ocupação.

\section{CONSIDERAÇÕES FINAIS}

Iniciou-se essa pesquisa com a hipótese de que o dinheiro teve grande influência no êxito eleitoral, o que foi revelado positivamente com os testes. O dinheiro teve grande influência no total de votos recebidos em todos os ciclos eleitorais investigados, inclusive na campanha de 2016, que contou com um aporte de receitas menor.

Destaca-se que no campo político o início das barreiras impostas ao sexo feminino se encontra no registro formal, o número de mulheres que têm suas candidaturas consideradas inaptas é maior que a dos homens. As não candidatas são mulheres menos escolarizadas, ocupam níveis de ocupação mais baixos, com recursos escassos e que não possuem carreira política.

Constatou-se que as mulheres se encontram nos quartis mais baixos de receitas, o fato de ser mulher diminuiu as chances de eleição em todos os ciclos eleitorais estudados comparada aos homens. E as variáveis que mais explicaram o sucesso eleitoral foi ter uma carreira política e ser incumbente, porém nada comparada, ao fator "maiores receitas". Os candidatos que possuem maiores receitas apresentaram mais de 184 vezes mais chances que os concorrentes, isso em todos os ciclos eleitorais. Destaca-se que ficou explícito a correspondência entre receita e sucesso eleitoral, mesmo que o sucesso eleitoral das mulheres seja reduzido, ocorre na mesma proporção que dispõem de receitas, ou seja, com maiores receitas, as chances do sucesso eleitoral sobem.

Ao se analisar os atributos pertencentes as mulheres, encontrou-se um perfil entre as eleitas: mulheres mais escolarizadas (nível superior), ocupando cargos de níveis superiores, com carreiras políticas e incumbentes. Entretanto, há uma exigência maior para elas na decisão eleitoral do que 
BUENO, A. A. M.; JUNCKES, I. J. Dinheiro, democracia e a (sub) representação das mulheres nas eleições de 2008, 2012 e 2016 no Brasil. DOI: http://dx.doi.org/10.5380/recp.v11i2.81598

para eles, a grande maioria das mulheres só consegue se eleger em níveis superiores de escolaridade e ocupação. Não se encontrou diferenças quando os candidatos (as) possuem carreiras políticas e são incumbentes, isso em 2008 e 2012, já em 2016 houve diferença, indicando o aumento das desigualdades.

Conforme apontado nas pesquisas existentes, pode-se concluir que a política municipal também apresenta um perfil em sua elite. A receita, incumbência, carreira política, seguidos de instrução e ocupação dos candidatos demonstraram ser fatores que geram desigualdades nas disputas eleitorais. Confirmando a grande influência do dinheiro nos resultados eleitorais, o que transforma a democracia em plutocracia, é evidente que as desigualdades socioeconômicas produzem outras desigualdades, como a exclusão do cenário político.

Para a participação plena e igualitária das mulheres na vida pública, além de ampliar as vagas de participação e ocorrer uma mudança na forma com que os partidos distribuem recurso e apoio, uma transformação na esfera doméstica é fundamental. Espera-se que a presente pesquisa, por sua abrangência territorial e temporal, possa se somar as demais, fortalecendo as evidências de desigualdades de gênero, com o intuito de que políticas públicas sejam desenvolvidas para ampliar a participação das mulheres.

\section{REFERÊNCIAS}

ARAÚJO, C. (2005). Partidos políticos e gênero: mediações nas rotas de ingresso das mulheres na representação política. Revista de Sociologia e Política, Curitiba, n. 24, p. 193-215, jun.

ARAÚJO, C.; ALVES, J. E. D. (2007). Impactos de indicadores sociais e do sistema eleitoral sobre as chances das mulheres nas eleições e suas interações com as cotas. Dados - Revista de Ciências Sociais, Rio de janeiro, vol. 50, n. 3, p. 535-577.

AVELAR, L. (2001). Mulheres na elite política brasileira. São Paulo: Fundação Konrad Adenauer: Editora da UNESP.

BOLOGNESI, B; PERISSINOTTO, R. M.; CODATO, A. (2016). "Reclutamiento político en Brasil: mujeres, negros Y partidos en las elecciones federales de 2014." Revista Mexicana de Ciencias Politicas Y Sociales, México, vol. 61, n. 226, p. 183-212, jan./abr.

BOLOGNESI, B. (2012). A cota eleitoral de gênero: política pública ou engenharia partidária? Paraná eleitoral: Revista de Direito Eleitoral e Ciência Politica. Curitiba, vol. 1, n. 2, p. 113-129, jun.

CARLOMAGNO, M. C.; CODATO, A. (2018). Profissão, sexo e dinheiro: mensuração da acumulação de desigualdades na competição eleitoral brasileira. Colômbia Internacional, Colômbia, n. 95, p. 79-107, jul./set. 
BUENO, A. A. M.; JUNCKES, I. J. Dinheiro, democracia e a (sub) representação das mulheres nas eleições de 2008, 2012 e 2016 no Brasil. DOI: http:/ /dx.doi.org/10.5380/recp.v11i2.81598

CERVI, E. U.; BORBA, F. (2019). Os diretórios partidários municipais e o perfil sociodemográfico dos seus membros. Revista Brasileira de Ciência Política, Brasília, n. 28, p. 65-92, jan./abr.

CODATO, A.; CERVI, E.; PERISSINOTTO, R. (2013). Quem se elege prefeito no Brasil? Condicionantes do sucesso eleitoral em 2012. Cadernos Adenauer, Rio de Janeiro, vol. 14, n. 2, p. 61 84.

DESCHAMPS, J. P. (2019). Desenvolvimento e democracia: uma análise do dinheiro e do sucesso eleitoral nas eleições municipais no Brasil (2008, 2012 e 2016). Matinhos. Dissertação (Mestrado em Desenvolvimento Territorial e Sustentável). Universidade Federal do Paraná - Setor Litoral.

DUflOTH, S. C.; HORTA, C. J.; SILVA, M. M.; COSTA M. L.; ROCHA, M. S. (2018). "Atributos e chances de sucesso eleitoral de prefeitos no Brasil". Revista de Administração Pública, Rio de Janeiro, vol. 53, n. 1, p. 214-234, mar.

FIGUEIREDO FILHO, D. B.; SILVA JUNIOR, J. A. da. (2009). Desvendando os mistérios do coeficiente de correlação de Pearson (r). Revista Política Hoje, Pernambuco, vol. 18, n. 1, p. 115-146.

JUNCKES, I. J. et al. (2015). Posicionamento das Mulheres na Rede de Financiamento Eleitoral e seu Desempenho nas Eleições de 2010 no Brasil: a dinâmica estrutural da exclusão e marginalização feminina no poder político. Revista Latino-Americana de Geografia e Gênero, Ponta Grossa, vol. 6, n. 1, p. $25-47$, jan./jul.

JUNCKES, I. J. et al. (2019). Poder e democracia: Uma análise da rede de financiamento eleitoral em 2014 no Brasil. Revista brasileira de Ciências Sociais, São Paulo, vol. 34 n.100. p.1-22, fev.

MANCUSO, W. P. (2015). Investimento eleitoral no Brasil: balanço da literatura (2001-2012) e agenda de pesquisa. Revista de Sociologia Política, Curitiba, vol. 23, n. 54, p. 155-183, jun.

MANCUSO, W. P.; HOROCHOVSKI, R. R.; CAMARGO, N. F. (2018). Financiamento eleitoral empresarial direto e indireto nas eleições nacionais de 2014. Revista Brasileira de Ciência Politica, Brasilia, n. 27, p. 9-36, dez.

MANCUSO, W. P.; SPECK, B. W. (2014). Financiamento de campanhas e prestação de contas. Cadernos Adenauer, Rio de Janeiro, vol. 15, n. 1, p. 135-150, ago.

MIGUEL, L. F. (2000). Teoria política feminista e liberalismo: o caso das cotas de representação. Revista Brasileira de Ciências Sociais, São Paulo, vol. 15, n. 44, p. 91-102, out.

MIGUEL, L. F.; QUEIROZ, C. M. de. (2006). Regional differences and women's relative success at municipal elections in Brazil. Revista Estudos Feministas, Florianópolis, vol. 14, n. 2, p. 363-385, ag.

MILL, Stuart. (2006). A sujeição das mulheres (1869). São Paulo: Ed. Escala.

MORAES, M. L. Q. (2015). "Prefácio da obra reivindicação dos direitos das mulheres". In: WOLLSTONECRAFT, Mary. Reivindicação dos direitos das mulheres. Tradução e notas de Andreia Reis do Carmo. São Paulo: Boitempo editorial.

PATEMAN, C. (2013). Críticas feministas a dicotomia público/privado. In: MIGUEL, L. F.; BIROLI, F. (orgs). Teoria politica feminista: textos centrais. Niterói: Editora da UFF, p. 55-79. 
BUENO, A. A. M.; JUNCKES, I. J. Dinheiro, democracia e a (sub) representação das mulheres nas eleições de 2008, 2012 e 2016 no Brasil. DOI: http:/ / dx.doi.org/10.5380/recp.v11i2.81598

PEIXOTO, V.; SILVA, G. T. da. Representação política de mulheres nas eleições municipais de 2016. In: VEIGA, L. F.; RIBEIRO, E. A.; GIMENES, E. R. (Orgs). Comportamento político e opinião pública: estudos sobre Brasil e América Latina. Curitiba: CPOP, 2018.

PERISSINOTTO, R. et al. (2007). Quem governa? Um estudo das elites políticas do Paraná. Curitiba: Editora UFPR.

PERISSINOTTO, R. M.; MIRÍADE, A. (2009). Caminhos para o parlamento: candidatos e eleitos nas eleições para deputado federal em 2006. Dados -Revista de Ciências Sociais, Rio de Janeiro, vol. 52, n. 2, p. 301-333, jun.

PHILLIPS, A. (2011). O que há de errado com a democracia liberal? Revista Brasileira de Ciência Política, Brasília, n. 6, p. 339-363, jul./dez.

SACCHET, T. (2018). Why gender quotas don't work in Brazil? The role of the electoral system and political finance. Colombia Internacional, Colômbia, n. 95, p. 25-54, jul.

SACCHET, T.; SPECK, B. (2010). Financiamento eleitoral e representação política: o peso do dinheiro e o desequilíbrio de gênero nas esferas legislativas. In: Congresso da ANPOCS, Caxambu.

SACHET, T. et al. (2012). Financiamento de campanhas de homens e mulheres candidatos a deputado estadual e deputado federal nas eleições gerais de 2010 no Brasil. In: MENEGUELLO, R. et al. Mulheres e negros na politica: estudo exploratório sobre o desempenho eleitoral em quatro estados brasileiros. Campinas, SP: UNICAMP/CESOP.

SCOTT, J. W. (2005). O enigma da igualdade. Florianópolis. Revista estudos feministas, Florianópolis, vol. 13, n. 1, p. 11-30, jan.

SILVA, B. F. da; CERVI, Emerson Urizzi. (2017). Padrões de financiamento eleitoral no Brasil: as receitas de postulantes à Câmara dos Deputados em 2010 e 2014. Revista Brasileira de Ciência Política, Brasília, vol. 23, p. 75-110, ago.

SILVA, B. F. da. (2016). O que (não) mudará com a proibição do financiamento empresarial às campanhas eleitorais no Brasil. Curitiba. Newsletter, Observatório de elites políticas e sociais do brasil. v. 3, n.12, ago.

SILVA, E. A. et al. (2017). Mulheres nas Eleições de 2014 no Brasil: Evidências de Exclusão e Marginalização Política. Revista Latino-Americana de Geografia e Gênero, Ponta Grossa, vol. 8, n. 1, p. 251-272., jan./jul.

SPECK, B. W. (2016). Game over: duas décadas de financiamento de campanhas com doações de empresas no Brasil. Revista de Estudios Brasileños, Salamanca, vol. 3, n. 4, p. 125-135, jan./jun.

SPECK, B. W.; SACCHET, T. (2012). Patrimônio, instrução e ocupação dos candidatos: uma análise das candidaturas de mulheres e homens nas eleições gerais de 2010 no Brasil. In: ALVES, J. E. D.; PINTO, C. R. J.; JORDÃO, F. (Org.). Mulheres nas eleições de 2010. São Paulo, ABCP. Associação Brasileira de Ciência Política. p. 167-206.

TELES, M. A. A. (1999). Breve história do feminismo no Brasil. São Paulo: Brasiliense. 